\title{
Hemolysis in E. coli O104:H4 Infection
}

\author{
Viroj Wiwanitkit
}

Received: 10 June 2011/Accepted: 25 August 2011/Published online: 4 September 2011

(C) Indian Society of Haematology \& Transfusion Medicine 2011

Sir, the present outbreak of Escherichia coli serotype O104: H4 in Europe is an important new emerging infection $[1,2]$. In addition to enteric pathology, the present infection also significantly induces the hemolysis. Indeed, some kinds of E. coli, especially for $\mathrm{O} 157$ can result in hemolysis and usually accompanied with renal disorder forming the specific syndrome called hemolytic-uremic syndrome [3]. Focusing on the first report E. coli O104: $\mathrm{H} 4$ infection by Bae et al., the hemolytic blood picture could be seen [4]. Nevertheless, several cases in present outbreak also present hemolysis. This reflects the possibility to induce hemolysis of this specific kind of $E$. coli that is similar to that of well-known E. coli O157. Nevertheless, there are still many remain questions to be answer on the hemolysis in E. coli O104: H4 infection including (a) the ultrastructure of the E. coli O104: $\mathrm{H} 4$ and relationship to hemolysis and (b) the clinical and treatment of this condition.

\section{References}

1. Tuffs RW (2011) European E. coli outbreak claims further victims. BMJ 342:d3610

2. Tuffs A (2011) Cause of outbreak of E. coli in Germany is still uncertain. BMJ 342:d3454

3. Clarke SC (2001) Diarrhoeagenic Escherichia coli-an emerging problem? Diagn Microbiol Infect Dis 41(3):93-98

4. Bae WK, Lee YK, Cho MS, Ma SK, Kim SW, Kim NH, Choi KC (2006) A case of hemolytic uremic syndrome caused by Escherichia coli O104:H4. Yonsei Med J 47(3):437-439

V. Wiwanitkit $(\bowtie)$

Wiwanitkit House, Bangkhae, Bangkok 10160, Thailand

e-mail:wviroj@yahoo.com 